\title{
Mathematical Modelling of High Voltage Gain Converter Using $P$ and $O$ for PV Based Application
}

\author{
Arunkumari Thiyagu ${ }^{1}$, Indragandhi $\mathrm{V}^{2^{*}}$, Ramani $\mathrm{Kannan}^{3}$ \\ ${ }^{1}$ School of Electrical Engineering, Vellore \\ ${ }^{2}$ School of Electrical Engineering, Vellore \\ ${ }^{3}$ Universiti Teknologi PETRONAS, Malaysia.
}

\begin{abstract}
This manuscript proposes a novel single switch converter which attains high voltage gain using $\mathrm{P}$ and $\mathrm{O}$ algorithm. The proposed converter is multilevel with voltage tripler technique. Here the output voltage gain attained is 11 times than the input source. The voltage ripple attained is less compared to other models. The main advantage of the converter is high efficiency, reduced switch loss, high gain and reduction in ripple. The converter attains efficiency of $97.3 \%$ at full load condition. The proposed converter is analysed by both Simulink MATALAB and Hardware prototype.
\end{abstract}

\section{Introduction}

The demand on power production and usage level has increased there is a need for alternative power production methods. Since the conventional sources are vanishing, this forces to the power production of the renewable energy. Also the main impact for it is, they are ecofriendly, pollution free, initial cost of source is free and they are bountiful in nature $[1,2]$. Hence the interest for renewable energy power generation has been increased. The renewable sources such as Photo voltaic (Solar), Wind, hydro, and tidal etc. The increase of solar energy has increased and the usage is also widely increased.

The solar energy is available in nature is free of cost but the solar panel cost initially high. This is a major drawback and hence it is not fully used as a main power generation sources. Also the solar energy production totally depends on the irradiation and temperature and if it differs the output voltage delivered also gets affected $[3,4]$. Hence many researchers working on this conditions to overcome and improve the efficiency of the PV system.

Several methodologies to attain Maximum Power Point Tracking (MPPT)[5] of PV module is developed to overwhelmed the efficiency problem and the system using this MPPT technique have been incorporated and it is directly available for the customers to use it [6]. There are several MPPT methods incorporated, they are hill climbing method, $\mathrm{P}$

*Corresponding author: arunindra08@gmail.ocom 
and $\mathrm{O}$ method, Particle swarm optimization, Bacterial Foraging algorithm, Ant colony algorithm, Bat algorithm, Flower pollination algorithm and etc..[7].

Here in this manuscript $\mathrm{P}$ and $\mathrm{O}$ method used due to its advantages. The structure of the algorithm is simple, less parameters and the iteration time is less. But power loss occurs in $\mathrm{P}$ and $\mathrm{O}$ method [8]. This MPPT is utilized in tracking maximum power even the solar energy is affected. This MPPT controller is utilized to control the DC-DC converter. These converters play a vital role in boosting up the voltage level. The PV voltage falls between 12$40 \mathrm{~V}$ to boost up the voltage level to $220,380,400 \mathrm{~V}$ DC-DC converter is needed[12-14]. Many techniques are incorporated in boost converter to improve the voltage gain among that coupled inductor is one method, where the voltage gain is improved but the number of components utilized is high which increases the size and space [15-17].

Then modified sepic converters are proposed but the voltage gain is less. Hence to overcome, a novel modified SEPIC converter with voltage tripler is proposed using $\mathrm{P}$ and $\mathrm{O}$ method in this manuscript. The proposed topology is well suitable for high voltage gain application. The manuscript is organized as below. In section 2, the PV cell modelling is explained. In section 3 operation of the proposed converter in CCM is explained. In section 4 the $\mathrm{P}$ and $\mathrm{O}$ controller of the proposed converter is explained. In section 5 Simulation results are evaluated. Conclusion is followed by section 6 .

\section{Operation of the proposed converter}

The proposed circuit is represented in Fig 1. Few assumptions are made to simplify the circuit designs and operation of the proposed converter.

The converter operates under continuous conduction mode at the steady state condition. Semiconductor devices are considered as ideal in nature.

The capacitor utilized has high storage voltage and hence the capacitors are assumed to be constant. Hence the input capacitor and the output capacitor are considered as equal.

The converter design consists of main switch $S_{1}$, inductors $L_{1}, L_{2}$, diodes $D_{1}, D_{2}, D_{3}, D_{4}, D_{5}$ and $D_{6}$, capacitors $C_{1}, C_{2}, C_{3}, C_{4}, C_{5}$ and output capacitor $C_{6}$. The VT circuit is combined with sepic converter to improve the voltage gain level of the converter. The switching voltage in the semiconductor device is reduced. Capacitors operate as similar operation in conventional boost converter.

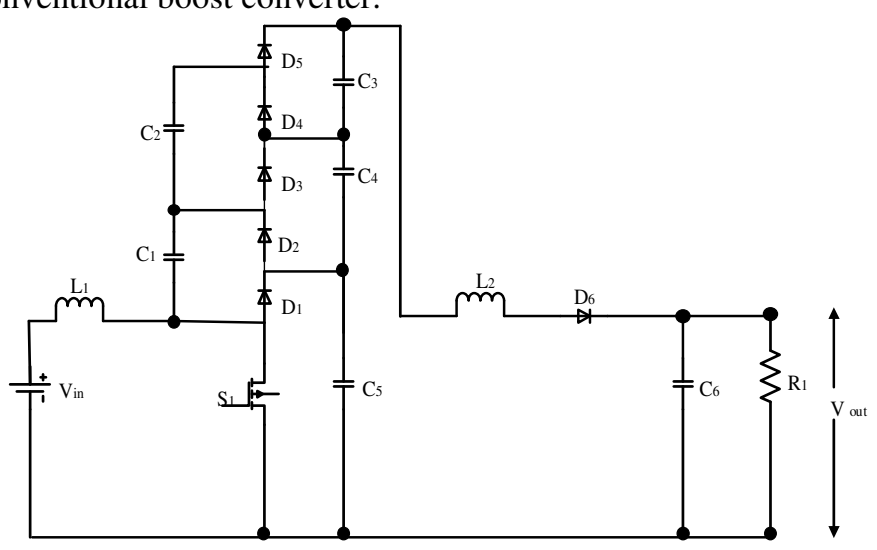

Fig.1 proposed single switch DC-DC Converter

\subsection{Continuous conduction mode operation}


The proposed converter operates in two modes. The modes of operations are shown in Fig.6 and Fig.7

Mode I [ $t 0-t 1]$ : When the switch $S_{1}$ is turned-on diodes $D_{2}, D_{4}$ and $D_{6}$ is turned ON. Diode $D_{1}, D_{3}$ and $D_{5}$ are reverse biased. The voltage $V_{i n}$ is delivered to $L_{1}$ and $\mathrm{V}_{\mathrm{C} 3}-\mathrm{V}_{\mathrm{C} 2}-\mathrm{V}_{\mathrm{C} 1}$ is delivered to $L_{2}$. These inductors help in storing the energy. The Output capacitor $C_{0}$ discharges the required energy to the load for its operation. When the switch turns off, this mode ends. Also the diode $D_{3}$ and $D_{0}$ current attains zero at $\mathrm{t}=\mathrm{t}_{1}$.

Mode II [t1-t2]: When the switch $S_{2}$, is turned OFF, the diodes $\mathrm{D}_{2}$ and $\mathrm{D}_{4}$ are in OFF condition. The diodes $\mathrm{D}_{1}, \mathrm{D}_{3}$ and $\mathrm{D}_{5}$ are in forward condition. The capacitors are charged by the inductor $\mathrm{L}_{1}$ and $\mathrm{L}_{2}$. The load receives the energy by discharging mode of the capacitor. This operation ends when Switch is turned ON. The next cycle continues.

The main operational waveform is represented in fig. 2 . The total capacitive voltage is equal to the output voltage of the converter.

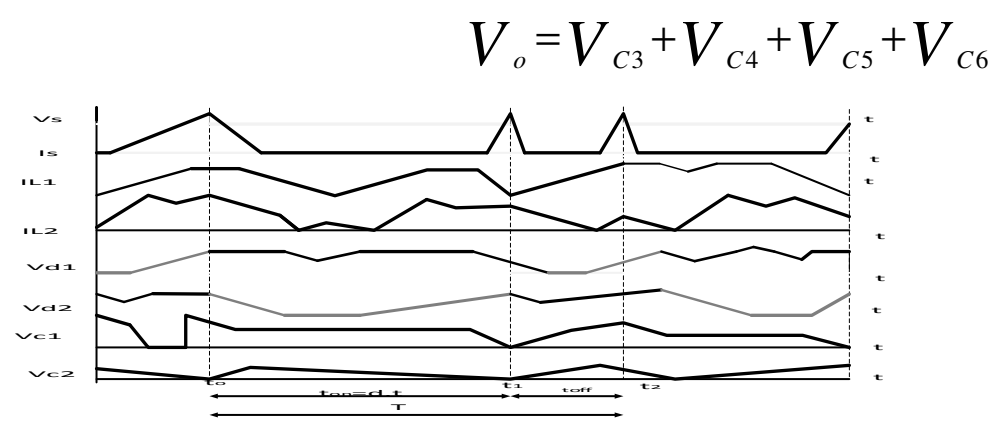

Fig. 2.CCM operation waveforms

\section{$3 \mathrm{P}$ and $\mathrm{O}$ controller for the proposed converter}

To increase the efficiency of the PV panel MPPT is utilized. According to MPPT, output power of any device can be increased by altering source impedance identical to the load impedance, so the MPPT algorithm is equivalent to the problem of impedance matching. In present work, the proposed Converter is utilized as impedance matching device between input and output of the converter circuit. The flowchart of the $\mathrm{P}$ and $\mathrm{O}$ is depicted in fig. 3 . The MPPT algorithm is detailed below.

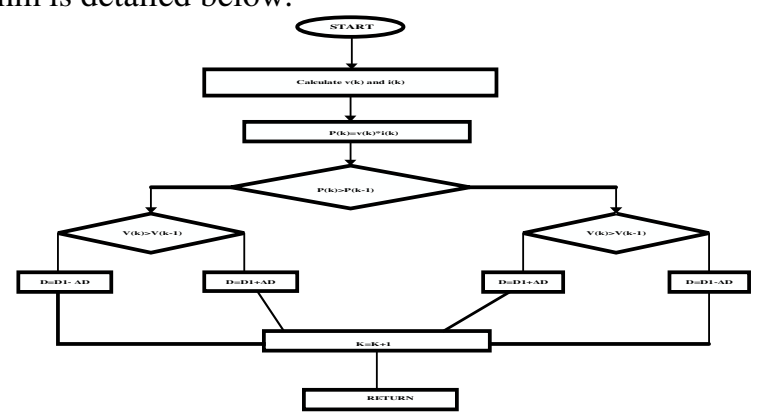

Fig.3 Flowchart for $\mathrm{P}$ and $\mathrm{O}$ controller

\section{Results and analysis}


The proposed converter is tested under Simulink MATLAB. The result of the proposed converter is depicted in the below figures. The transient response of the proposed converter is analysed and compared with other converter. The transient response of the proposed converter is better than other converters and its depicted in table. 1

Table 1: Transient response analysis:

\begin{tabular}{|l|c|c|}
\hline Transient response & Boost Converter & Proposed Converter \\
\hline Settling time & $0.9 \mathrm{~ms}$ & $0.15 \mathrm{~ms}$ \\
\hline Peak time & $0.09 \mathrm{~ms}$ & $0.03 \mathrm{~ms}$ \\
\hline Rise time & $0.08 \mathrm{~ms}$ & $0.014 \mathrm{~ms}$ \\
\hline Maximum overshoot & $5 \%$ & 0 \\
\hline Steady state error & $2.6 \%$ & 0.25 or $0.6 \%$ \\
\hline
\end{tabular}

\subsection{Simulation results}

The proposed converter is implemented with $\mathrm{P}$ and $\mathrm{O}$ controller for PV based application and it is tested under simulation. The input voltage and current waveforms are implemented in fig.4. And the output voltage and current waveforms are depicted in fig.5.
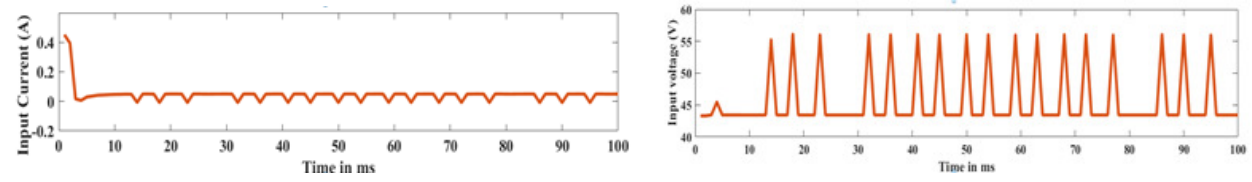

Fig.4 Input voltage , current and power
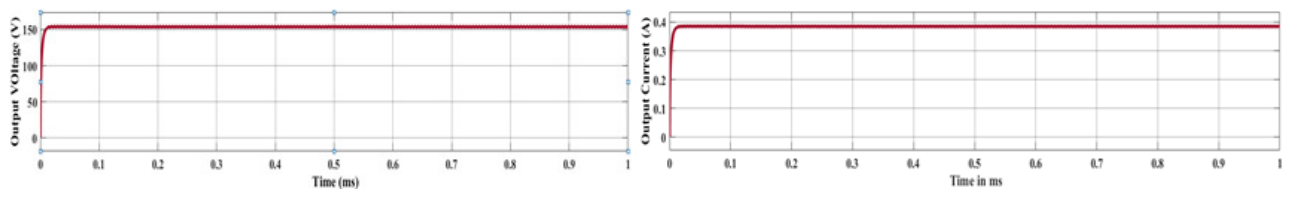

Fig. 5 Output voltage, current waveform

The proposed converter improves the voltage from $30-40 \mathrm{~V}$ to $160 \mathrm{~V}$ with less duty cycle and high voltage gain. The efficiency percentage of the proposed converter is $94 \%$. The transient response of the proposed converter is analysed and its better than other converters.

\section{Conclusion}

The high gain converter is proposed in this manuscript. The proposed converter is utilized for PV based applications. The modelling of PV source is discussed and the proposed converter operations are explained. The $\mathrm{P}$ and $\mathrm{O}$ controller is implemented with the proposed converter for control operation and to fix the maximum voltage level. This controller maintains the converter voltage even when there is a disturbance in line or load. The 
simulation results of the model demonstrated is depicted. The future work of this model is to be carried out as experimental analysis.

\section{References}

1. M.T. Amelia, S. Moslehpourb, M. Shamloa. EPSR; 7 pp-1147-52 (2008).

2. AR. Reisi, MH. Moradi, S. Jamasb, RSER;19 (2013)

3. Y.-H.Chang and C.-Y. Chang, at International Multi Conference of Engineers and Computer Scientists Hong Kong, (2010).

4. S. Mekhilef, JPE, 1, pp. 49-62 (2008).

5. S. Saravanan, N. Ramesh Babu. RSER 57:197-204 (2016).

6. C. Zhang and D. Zhao. 4th IEEE Conference .(2009)

7. L.B. Wu., Z.M. Zhao, L J.Z., iu, Wamgand Liu, S., Proceedings-Chinese Society of Electrical Engineering 26.(2006)

8. S. Qin,., M.Wang,., T. Chen, and Yao, .Proceedings-Chinese Society Of Electrical Engineering. (2011)

9. G. Graditi, G. Adinolfi. and G.M., Tina,. AE, 115, pp.140-150 (2014).

10. J. Park. and S. Kim,. JEM, 6, pp.1242-1246. (2012)

11. J.L Santos, F Antunes., A Chehab and C. Cruz, SE, 7, pp.772-778 (2006).

12. M. Kalantar, . AE, 10 (2010)

13. Y. Hu. W., Cao and X .Chen,., RE, 74 (2015)

14. A.J. Sabzali, and E.H., Ismail. In ICREGA'14 Generation and Application Springer,(2014)

15. X Hu, and X.Gong., IEEE, 2, (2014).

16. L.S. Yang, Liang, T.J., Lee, H.C. and J.F .Chen,.., 2011.. IEEE 9, pp.4196-4206 (2011).

17. T. Arunkumari, and V., Indragandhi. RSER, 77, pp.670-687. (2017) 